\section{An Economic Assessment of the Impact of Huanglongbing on Citrus Tree Plantings in Florida}

\author{
Thomas H. Spreen ${ }^{1,4}$ \\ University of Florida, Food and Resource Economics Department, McCarty \\ Hall A (MCCA), P.O. Box 110240, Gainesville, FL 32611-0240
}

\author{
Jean-Paul Baldwin ${ }^{2}$ \\ Miami University, Department of Information Systems and Analytics, Oxford, \\ OH 45056-3653
}

\author{
Stephen H. Futch ${ }^{3}$ \\ University of Florida, IFAS, Citrus Research and Education Center, 700 \\ Experiment Station Road, Lake Alfred, FL 33850-2299
}

Additional index words. citrus production, economics, huanglongbing, plantings

\begin{abstract}
Huanglongbing (HLB) was first discovered in Florida in 2005. It can now be found in all counties in the state where commercial citrus production takes place. HLB is a bacterial disease that is transmitted by the Asiatic citrus psyllid. HLB negatively affects citrus producers in several ways, including reduced yield, increased grove maintenance costs, and increased tree mortality. The research presented in this article suggests that another consequence of HLB is its adverse effect on the willingness of producers to invest in new plantings. Reduced plantings imply reduced fruit production in the future.
\end{abstract}

Huanglongbing is a bacterial disease of citrus that until recently was confined to Asia and Africa. In 2004, the first discovery of the disease in the Western Hemisphere was in Sao Paulo, Brazil. In 2005, the disease was first discovered in Florida. Since then, it has spread rapidly and now can be found in all counties in Florida that contain commercially produced citrus. HLB represents one of the strongest threats to the largest citrus-producing state in the United States. In the 2007-08 season, Hodges and Rahmani (2009) estimated that the economic value of the citrus industry on the economy of Florida was $\$ 8.9$ billion.

HLB affects citrus trees by blocking the phloem or the vascular system of the tree, limiting its ability to transport nutrients within the plant. It is spread by a small leaf-feeding insect: the Asiatic Citrus Psyllid (ACP), Diaphorina citri Kuwayama. The characteristics of the disease are mottled leaves and small misshapen fruit. Increased fruit drop is associated with the disease; but even if fruit remains on the tree until harvest, the fruit is undersized and contains bitter or off-flavor juice, rendering it of no economic value.

The disease first appeared in China in the early 20 th century. It was first called "yellow shoot disease." Lin and Lin (1956) are

\footnotetext{
Received for publication 17 Apr. 2014. Accepted for publication 27 June 2014.

${ }^{1}$ Professor Emeritus.

${ }^{2}$ Visiting Assistant Professor.

${ }^{3}$ Extension Agent.

${ }^{4}$ To whom request reprints should be addressed; e-mail tspreen@ufl.edu.
}

credited with first identifying the disease and gave it the name HLB. They found the disease in several provinces of southern China.

Two approaches have evolved to combat the disease. The first approach is to immediately remove any tree exhibiting symptoms of the disease. The second approach is a nutritionalbased program. The first approach is generally credited to Bové (2006). In the Bové approach, an aggressive scouting program is initiated. Any tree found that exhibits symptoms of HLB is immediately eradicated. A program to suppress the ACP population is also initiated.

One drawback of the Bove program is that infected trees may not exhibit symptoms for up to 2 years (in the case of mature trees) after becoming infected. Thus, eradicating only symptomatic trees will not eliminate the disease. Diligent implementation of this approach should suppress the level of disease inoculum over time so that annual tree losses are economically tolerable. Another disadvantage of this approach is the so-called "bad neighbor" effect. If a single grower among a contiguous planting fails to follow the Bové approach, their grove will continue to serve as a source of inoculum. Another issue is that if the level of infection is too high before the disease is discovered, it may be necessary to eradicate an entire block.

University of Florida economists have estimated that the Bové method increases per-acre grove maintenance costs by $\approx \$ 400$ was first found in Florida (Muraro). With rapid escalation of input costs, especially fertilizer, estimated annual grove maintenance costs annually, an increase of $33 \%$ since the disease of Florida are now placed at nearly $\$ 2000$ per acre ( $\$ 4942$ per ha), which does not include harvesting cost. As bearing tree numbers decrease, per-acre yields will also decrease.

A grower in southwest Florida, faced with a high of level of infection, decided to implement another approach to deal with HLB. Because HLB blocks the phloem of citrus trees, he devised an approach of feeding trees through their leaves, thus bypassing the phloem transport issue. This approach is known as enhanced foliar nutrition. Under this approach, scouting for the disease is halted, and symptomatic trees are not eradicated. This approach has shown some success in masking the effects of the disease, enabling trees to produce significant volumes of fruit. It elevates the cost of grove maintenance, ranging from $\$ 200$ to $\$ 600$ per acre (\$494 to $\$ 1483$ per ha) (Roka et al., 2010).

The purpose of this article is to examine the impact of the presence of HLB on new tree plantings in the Florida citrus industry. Sweet oranges are by far the most prevalent citrus scion grown in Florida, so the analysis is limited to sweet orange plantings. HLB impacts citrus producers through reduced yield, increased tree mortality, and increased cost of production; it is expected that the presence of HLB has had an adverse impact on growers' willingness to invest in new plantings. The estimated impact is used in a fruit production model to project the impact on future fruit production in Florida.

\section{Theoretical Considerations}

Citrus growers adjust output through investment in new plantings. The economics of new grove investment in citrus have been previously studied by several authors including Kalaitzandonakes and Shonkwiler (1992) and Spreen et al. (2003). In both of these studies, new citrus tree plantings were found to be 1) related to past prices; and 2) highly autoregressive. In this article, a hybrid model that follows along the line of both Kalaitzandonakes and Shonkwiler (1992) and Spreen et al. (2003) is used in which new plantings in period $t$, denoted by $\mathrm{NP}_{t}$, is modeled as a function of past plantings, $\mathrm{NP}_{\mathrm{t}-1}$, and lagged grower prices, $\mathrm{P}_{\mathrm{t}-1}$. Grove maintenance costs, $\mathrm{C}_{t}$, as compiled by the University of Florida on an annual basis, are also included as an explanatory variable. In a linear specification, this model is

$$
\begin{aligned}
\mathrm{NP}_{\mathrm{t}}= & \beta_{0}+\beta_{1} \mathrm{P}_{\mathrm{t}-1}+\beta_{2} \mathrm{NP}_{\mathrm{t}-1} \\
& +\beta_{3} \mathrm{CT}_{\mathrm{t}-1}+\beta_{4} \mathrm{HLB}_{\mathrm{t}}+\varepsilon_{\mathrm{t}}
\end{aligned}
$$

where the $\beta$ s are parameters to be estimated and $\varepsilon_{\mathrm{t}}$ is a random disturbance term.

To account for the effect of HLB on new tree plantings, a dummy variable approach is used. This variable $\left(\mathrm{HLB}_{\mathrm{t}}\right)$ takes on the value 1 for years 2006-07 and later and zero otherwise. If the presence of HLB has had an adverse effect on plantings, it is expected that the parameter on this variable will be statistically significant with a negative sign. 


\section{Data}

Data on new plantings of round oranges disaggregated into early- and midseasonmaturing (early-mid) and Valencia (late-season) varieties are reported by the Florida Agricultural Statistics Service (FASS, 2011-12). Grower (on-tree) prices, also disaggregated into early-mid and Valencia varieties, are also reported. For this analysis, the data cover the period extending from the 1989-90 season through the 2010-11 season. The decade of the 1980s saw several major freezes to the citrus region of Florida, which spurred a massive replanting in south Florida and therefore was excluded from this analysis.

Grove maintenance costs for Florida citrus is compiled annually by Muraro and associates. These data were assembled for the same time interval, 1989-90 through 2010-11.

In Figure 1, total orange tree plantings in Florida are shown over the sample period. The high level of plantings in the early 1990s was in response to high grower prices associated with reduced supply of juice oranges after the freezes of the 1980s. As grower prices declined in the latter portion of the 1990s, so did new tree plantings. Multiple hurricanes occurred in Florida's citrus-growing regions in both 2004-05 and 2005-06 crop years. Reduced supply of oranges caused prices to rise, but note the failure of new plantings to respond to higher prices and associated risks of citrus canker and later HLB beginning in 2005.

\section{Statistical Analysis}

The model [Eq. (1)] depicts new plantings in time period $t$ as a function of grower price, new plantings, and cost in period t- 1 as well as a dummy variable that indicates the presence of HLB in period t. Lagged new plantings are included to account for the presence of probable serial correlation occurrences within time series models. Disaggregating new plantings into early-mid and Valencia varieties, two separate regression models are estimated with their explanatory variables corresponding to the specific variety. Cost was introduced as an explanatory variable in predicting new plantings; however, preliminary results indicate insignificant explanatory power of this variable and, as a consequence, the variable was removed from the analysis.

Parameter estimates and associated statistics for the model are shown in Table 1. For

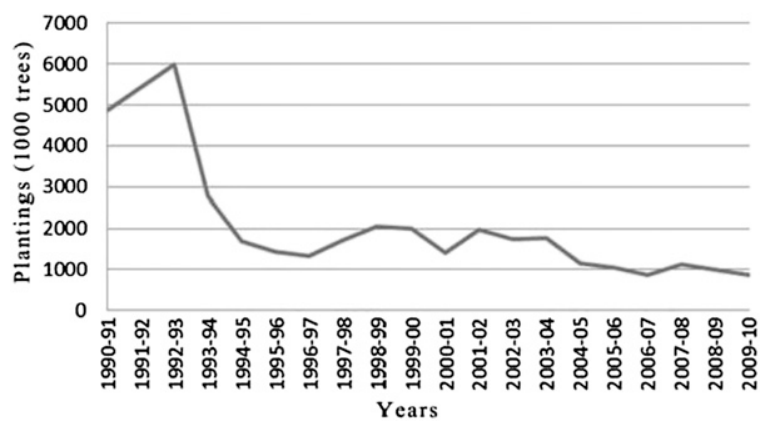

Fig. 1. Total Florida tree plantings in 1000 trees (1990-2010). each model, the inclusion of lagged new plantings and grower prices is seen as highly significant. The positive parameters associated with these variables imply that, everything else being equal, an increase in previous years' planting and prices results in increased new plantings. This is consistent with a priori expectations based on previous observations. The dummy variable (HLB) is significant within both early-mid and Valencia models, attaining levels of significance within $95 \%$ and $90 \%$, respectively. The negative sign on the parameter provides evidence in explaining the expected adverse effect of HLB on willingness to invest in new trees.

The Durbin-h statistic indicated suggested that the inclusion of the lagged dependent variable in the model resolved any issues associated with possible serial correlation.

A striking result of the regression results is the magnitude of the estimated coefficient on the HLB dummy variable in both the early-mid and Valencia new planting equations. The coefficient in the early-mid equation is -779.02 , which suggests that each year the presence of HLB reduces new plantings of early and midmaturing varieties by 779,000 trees. In $2011, \approx 550,000$ early-mid trees were planted. Therefore, the HLB effect reduced potential new plantings by more than $50 \%$. The coefficient of the HLB dummy variable in the Valencia equation is -585.16 ; the estimated number of Valencia new tree plantings in 2011 was $\approx 490,000$. Again, effect reduced potential new plantings by more than $50 \%$.

\section{Implications of the Regression Results}

Using the world orange juice model first developed by McClain (1989) and later modified by Spreen et al. (2003) and Spreen and Jauregui (2009), the implications of the negative effect of the presence of HLB on future orange production in Florida can be simulated.

The world orange juice model is a spatial equilibrium model of the world orange juice market. It includes Florida and Sao Paulo, Brazil, who collectively account for over $80 \%$ of the world's orange juice supply as endogenous supply regions. Production from Mexico, California, and Central America (Belize and Costa Rica) is included at fixed levels. Demand regions include the United States, the European Union, Canada, and the rest of the world. In the United States and Canada, demand is disaggregated into notfrom-concentrate (NFC) and frozen concentrate orange juice (FCOJ) consumption.

Using the tree inventory compiled for Florida and Sao Paulo, orange production is generated. A fixed amount is deducted to account for fresh orange use, and the remainder is converted to orange juice using historical juice yield data. This juice is allocated across the four regional markets and across NFC and FCOJ through a mathematical programming model (Spreen et al., 2003). Once a spatial and product form, price equilibrium has been established, prices in each of the demand markets are determined. Adjusting for tariffs (if any), transportation, processing, and harvest costs, grower (ontree) prices are determined. These prices are then used as input into a new planting equation. The tree inventory is aged and adjusted for tree mortality, and the model is solved again for the next season.

The model has been validated for the 2011-12 marketing year. It is then run under two scenarios: with the HLB dummy variable in the new planting equation and without the HLB dummy variable. The results are summarized in Figures 2 and 3.

In Figure 2, projected Florida orange production in millions of $90-1 b$ boxes is shown over the 2011-12 to 2031-32 period. With the HLB effect on new plantings included, sweet orange production is expected to diminish slightly over the next 10 seasons and then, in response to higher prices, recover to almost 150 million boxes $(6.123$ million metric tons). In the 2011-12 season, actual production was 146.5 million boxes $(5.980$ million metric tons). If the HLB effect is deleted, production is projected to remain relatively flat for the next five seasons and then rise reaching $\approx 225$ million boxes $(9.185$ million metric tons) by 2031-32. The data shown in Figure 3 support these observations; tree numbers remain relatively flat with HLB and exhibit a strong recovery without HLB.

This analysis assumes that no solution to HLB will be discovered within the next 20 years. Given the research dollars that are being allocated to finding solutions to HLB, it is likely that some sort of HLB-mitigating strategy will be found. This might be a disease-resistant tree, better control of the ACP, or antibiotic that can suppress the disease.

HLB is also found in Sao Paulo, Brazil, and this study ignores the HLB impact there. For the most part, larger growers in Sao Paulo have followed the Bove approach of aggressively scouting and eradicating symptomatic trees. This has been incorporated into the world orange juice model by increasing tree mortality rates in Sao Paulo. If a solution to HLB is discovered, that solution will also likely be used in Sao Paulo, thereby affecting the assumptions of the model.

\section{Limitations of the Analysis}

The 2012-13 season witnessed much higher rates of premature fruit drop, another 
Table 1. Regression results for early-mid and Valencia new plantings.

\begin{tabular}{lcc}
\hline & Early-mid & Valencia \\
\hline Constant & -334.8273 & -404.2493 \\
& $(306.1506)$ & $(298.6336)$ \\
Lagged new plantings & $0.5658283^{* * *}$ & $0.6897042^{* * *}$ \\
& $(0.1558799)$ & $(0.111694)$ \\
Grower prices & $210.5084 * *$ & $142.9528^{* *}$ \\
& $(88.61119)$ & $(63.52688)$ \\
HLB & $-779.092^{* *}$ & $-585.1652^{*}$ \\
$R^{2}$ & $(365.9027)$ & $(322.3179)$ \\
Adjusted $R^{2}$ & 0.6992 & 0.8329 \\
No. of observations & 0.6390 & 0.7995 \\
\end{tabular}

No. of observations

SES are reported in parentheses.

$*, * *, * * *$ indicate significance at the $90 \%, 95 \%$, and $99 \%$ level, respectively.

\section{Production: HLB vs No HLB Effect}

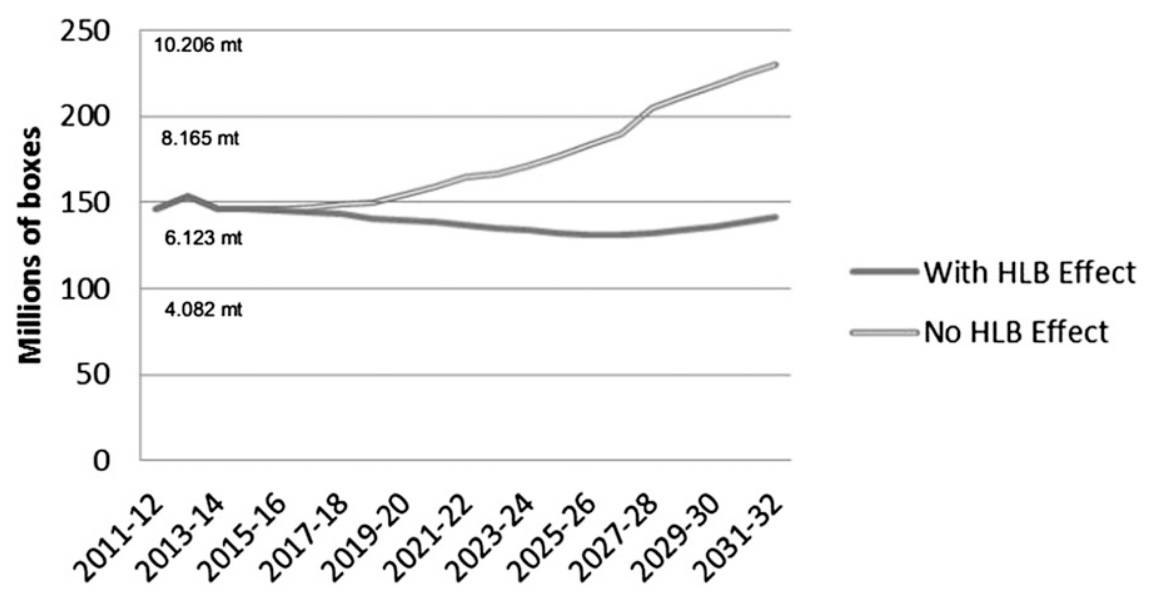

Fig. 2. Projected production [millions of 90-lb boxes or metric tons (mt)].

\section{Total Trees: HLB vs No HLB Effect}

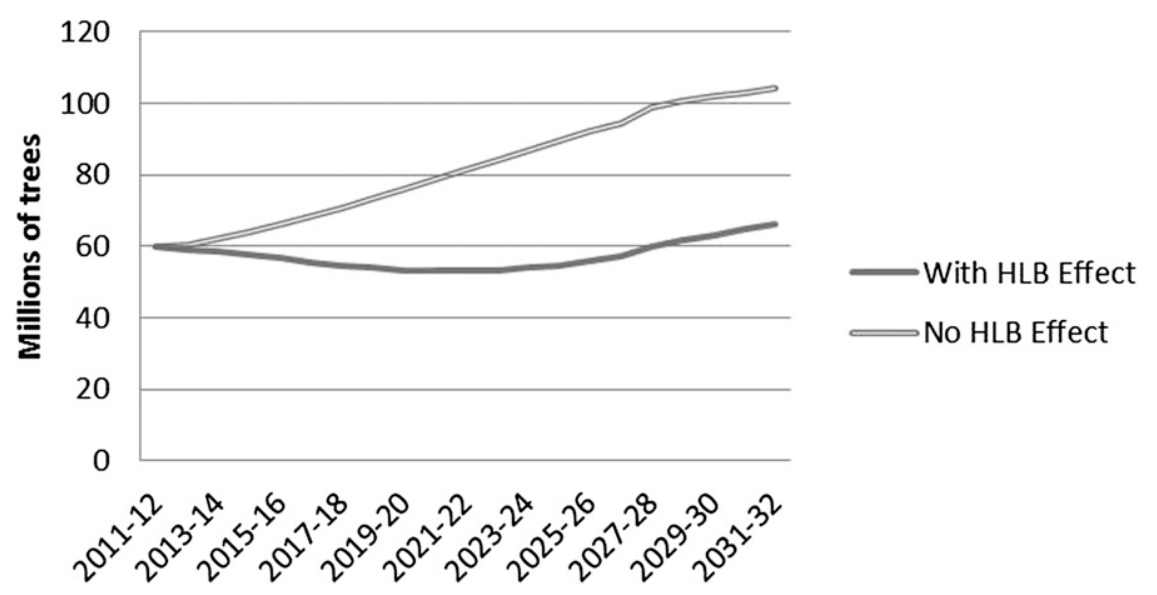

Fig. 3. Projected total trees (millions).

symptom associated with HLB. Therefore, the results depicted in Figure 2 may overstate future fruit production under the with HLB scenario. The 2013-14 Florida citrus crop forecast released in early Nov. 2013 indicates another small orange crop in Florida. Lower fruit yields and smaller fruit sizes in Florida are another dimension associated with HLB and is not explicitly considered in this analysis.

\section{Concluding Remarks}

Huanglongbing is a relatively new disease to the Florida citrus industry. The industry appears to have adopted a foliar nutrition approach in an attempt to mitigate the negative effects of the disease. The consequences of HLB are higher tree mortality, reduced yields, smaller fruit size, and higher grove maintenance costs, all of which have negative impacts on grove profitability. A causal examination of new plantings in Florida suggests the presence of HLB has reduced the willingness of Florida growers to invest in new plantings as a result of multiple risks.

Two new tree planting equations were estimated for Florida sweet oranges: early and midmaturing varieties and Valencias using data that spanned the period 1989-90 through 2010-11. Previous studies suggested that new plantings are a function of grower (on-tree) prices and lagged plantings. Grove maintenance costs were also collected and included in the regression equation but proved to not be a useful explanatory variable. To account for the possible impact of HLB, a dummy variable approach was used. The estimated coefficients for grower prices and lagged prices were statistically significant and of the correct sign. The estimated coefficient for the HLB variable was negative and quite large in magnitude, although it was statistically significant only at the $90 \%$ level for Valencias.

The estimated new planting equations were incorporated into the world orange juice model developed at the University of Florida. Simulations were produced for the period 2011-12 through 2031-32 in which the HLB effect was both included and excluded. As expected, these two simulations produced quite different projections for both future orange production and tree numbers in Florida. With HLB, Florida orange production is expected to remain at current levels of $\approx 125$ to 150 million boxes (5.102 to 6.123 million metric tons) or decrease; without HLB, Florida orange production is projected to increase to nearly 225 million boxes (9.185 million metric tons) by 2031-32.

Given the use of dummy variable approach to capture the effect of HLB on new citrus tree plantings, the main limitation of this article is that the measured HLB "effect" may be confounded with other factors that may have been present over the 2006-11 period. Although the housing boom of the mid-2000s led some growers to not rehabilitate their groves after the hurricanes of 2004 and 2005, this effect disappeared with the large declines in rural land prices after the housing bust of 2008. Another factor has been the large increase in overall input prices associated with high commodity prices, but these prices were included in the grove maintenance costs that were included in the preliminary regressions.

The adverse effect of HLB on the willingness of growers to invest in new plantings could be addressed in several ways. One large juice marketing company has introduced a 20-year fruit contract in an attempt to encourage new plantings. This contract applies only to groves that have been newly planted. Another approach that is being discussed is that juice companies may partner with growers 
by underwriting a portion of new grove investment, which then would be repaid from the proceeds of future fruit production. Another issue relates to tax treatment of newly planted groves. Under present tax rules, the investment required for new plantings cannot be depreciated until the grove begins to produce fruit. Then the investment is placed on a 7-year depreciation schedule. Because new trees generally do not bear fruit until the third or fourth year of life, this means that it takes 10 or 11 years to depreciate the grove for tax purposes.

The results presented here provide one measure of the adverse impact that HLB is imposing on the Florida citrus industry. The disease also has other dimensions of impact and continues to threaten the future viability of Florida citrus.

\section{Literature Cited}

Bové, J.M. 2006. Huanglongbing: A destructive, newly-emerging, century-old disease of citrus. J. Plant Pathol. 88:7-37.

Florida Agricultural Statistics Service (FASS). 2011-12. Florida Citrus Statistics. Fla. Dept. Agr. Cons. Serv. and Natl. Agr. Stat. Serv., U.S. Dept. Agr., Orlando, FL.

Hodges, A.W. and M. Rahmani. 2009. Economic impacts of the Florida citrus industry in 2007/ 08. Electronic Data Information Source (EDIS) FE802. Univ. of Fla., Gainesville, FL. June 2013. <http://edis.ifas.ufl.edu/fe802>.

Kalaitzandonakes, N.G. and J.S. Shonkwiler. 1992. A state-space approach to perennial crop supply response. Amer. J. Agr. Econ. 74:343-352.

Lin, K.H. and K.-H. Lin. 1956. The citrus huanglongbing (greening) disease in China. Acta Phytopathol. Sin. 2:1-11, 14-38.
McClain, E.A. 1989. A Monte Carlo simulation of the world orange juice market. Unpublished $\mathrm{PhD}$ diss., Univ. of Fla., Gainesville, FL.

Muraro, R.P. The cost of growing citrus in Central Florida. $<$ http://www.crec.ifas.ufl.edu/extension/ economics/>.

Roka, F., R. Muraro, and A. Morris. 2010. Economics of HLB management: Pull trees or spray nutritionals. Intl. Citrus Econ. Conf., Orlando, FL, Oct. 2010.

Spreen, T.H., C. Brewster, and M.G. Brown. 2003. The free trade area of the Americas and the world processed orange market. J. Agr. Appl. Econ. 35:107-126.

Spreen, T.H. and C. Jauregui. 2009. Generic advertising and the world orange juice market: Distribution of benefits. Brit. Fd. J. 111:852865 . 